\title{
EFEITO DE DIFERENTES TENSÕES DE ÁGUA NO SOLO SOBRE O DESENVOLVIMENTO INICIAL DO TOMATEIRO
}

Rogério Rangel Rodrigues ${ }^{1}$, Samuel Cola Pizetta ${ }^{2}$, Nicolly Kalliliny Cavalcanti Silva ${ }^{3}$, Fabian Enrique Diaz Pacheco ${ }^{4}$, Geraldo Magela Pereira ${ }^{5}$

1Doutorando em Recursos Hídricos em Sistemas Agrícolas. Universidade Federal de Lavras (UFLA), Lavras, MG, Brasil. E-mail: rogeriorr7@hotmail.com

${ }^{2}$ Doutorando em Recursos Hídricos em Sistemas Agrícolas. Universidade Federal de Lavras, Lavras, MG, Brasil.

${ }^{3}$ Mestra em Recursos Hídricos em Sistemas Agrícolas pela Universidade Federal de Lavras.

${ }^{4}$ Graduando em Agronomia. Universidade de Sucre, Sincelejo, Sucre, Bolívia. ${ }^{5}$ Professor do Programa de Pós-Graduação em Recursos Hídricos em Sistemas Agrícolas, UFLA/DEG, MG, Brasil.

Recebido em: 08/04/2016 - Aprovado em: 30/05/2016 - Publicado em: 20/06/2016 DOI: 10.18677/Enciclopedia_Biosfera_2016_047

\section{RESUMO}

Diferentes cultivares e variedade de tomateiro podem apresentar necessidade hídrica diferenciada, tornando-se indispensável o estudo da demanda hídrica por essas culturas. Desta forma, objetivou-se avaliar a influência de diferentes tensões de água no solo sobre o desenvolvimento do tomateiro cultivar Dominador F1, sob cultivo protegido e irrigado por gotejamento, em Lavras, MG. O experimento foi instalado em casa de vegetação com delineamento em blocos casualizados, com quatro repetições. Os tratamentos foram constituídos de seis níveis de tensões de água no solo como indicativos do momento de irrigar. As tensões preestabelecidas foram 20, 45, 70, 95, 120 e $145 \mathrm{kPa}$. Aos 64 dias após início dos tratamentos, as variáveis avaliadas foram: altura da planta, número de folhas, número de cachos, diâmetro do caule e número de frutos. Os resultados demonstraram que as variáveis avaliadas foram menores quando se aumentou a tensão de água no solo e que, para maiores valores, as irrigações devem ser realizadas quando a tensão de água no solo, a $0,20 \mathrm{~m}$ de profundidade, estiver em torno de $20 \mathrm{kPa}$.

PALAVRAS-CHAVE: Crescimento, Dominador F1, Solanum lycopersicon L.

\section{WATER STRESS EFFECT OF DIFFERENT SOIL ON THE INITIAL DEVELOPMENT OF TOMATO}

\begin{abstract}
Different cultivars and variety of tomato can have different water requirements, making it essential to study the water demand for these crops. Thus, this study aimed to evaluate the influence of different water tensions in soil on the development of tomato cultivar Dominator F1 under protected cultivation and irrigated by drip, in Lavras, MG. The experiment was conducted in a greenhouse in a randomized block
\end{abstract}


design with four replications. The treatments consisted of six levels of water tension in the soil as indicative of time to irrigate. The predetermined voltages were 20,45 , $70,95,120$ and $145 \mathrm{kPa}$. After 64 days after start of treatment, the variables were evaluated: plant height, leaf number, number of clusters, stem diameter and number of fruits. The results showed that the variables were lower when it increased the water tension in the soil and to higher values, the irrigations should be done when the water tension in the soil, to $0.20 \mathrm{~m}$ deep, is around $20 \mathrm{kPa}$.

KEYWORDS: Solanum lycopersicon L., Dominador F1, growth.

\section{INTRODUÇÃO}

O tomateiro (Solanum lycopersicon L.), cuja origem é a região andina, é uma das hortaliças mais cultivadas no mundo, sendo a China, Índia e Estados Unidos os maiores produtores. O Brasil atualmente se encontra em oitavo lugar entre os maiores produtores desta cultura, sendo a segunda hortaliça mais importante na economia, apresentando o estado de Goiás como o maior produtor (SGN, 2012; ALVARENGA, 2013; FAOSTAT, 2013; IBGE, 2013).

Para o cultivo do tomateiro o sistema de produção pode variar de acordo com a região, com o poder aquisitivo do produtor, quanto à classificação do grupo a que pertence o tomateiro, com o hábito de crescimento e com a cultivar. O clima pode ser um fator determinante na produção de hortaliças, tanto pelo excesso de chuvas no verão, quanto pelo frio e ventos fortes no inverno, podendo prolongar o ciclo da cultura ou danificá-la (ALVARENGA, 2013).

Devido a grande quantidade de água no fruto do tomateiro, em torno de 93 a $95 \%$, o manejo adequado da irrigação torna-se fator primordial (ALVARENGA, 2013). Tanto o déficit de água quanto o excesso resultam em danos à cultura, como rachaduras nos frutos, podridão apical, queda de flores e frutos, frutos ocos, menor produção de matéria seca, alteração no $\mathrm{pH}$, no teor de sólidos solúveis totais, alteração na troca gasosa, alteração na concentração de ácido abscísico, número de frutos comerciais, ataque de doença, alteração genética, no uso eficiente da água, na qualidade nutricional do tomate, entre outros danos (SÁ et al., 2005; OZBAHCE; TARI, 2010; SAMAILA et al., 2011; WANG et al., 2012; MUKHERJEE et al., 2012; SUN et al., 2013; KUŞÇU et al., 2014; HOTT et al., 2014).

Sendo assim, além da eficiência dos diferentes métodos e equipamentos utilizados no manejo da irrigação na cultura do tomate, pesquisas têm demonstrado que as diferentes cultivares, ambientes e práticas culturais adotadas no manejo do tomate em ambiente protegido têm sido a causa de variações na produtividade do tomateiro (GUALBERTO et al., 2007).

Diante do exposto, objetivou-se com este trabalho avaliar a influência de diferentes tensões de água no solo no desenvolvimento inicial do tomateiro, variedade Dominador F1.

\section{MATERIAL E MÉTODOS}

O experimento foi conduzido no campo experimental da Universidade Federal de Lavras (UFLA), no município de Lavras, MG, tendo como referência as seguintes coordenadas geográficas: latitude $21^{\circ} 13^{\prime} 54,18^{\prime \prime} \mathrm{S}$, longitude $45^{\circ} 58^{\prime} 35,18^{\prime \prime}$ W Gr. e $894 \mathrm{~m}$ de altitude. 
A cultura utilizada no experimento foi o tomateiro, variedade híbrida Dominador F1, do grupo Caqui/Salada. Esta variedade tem um ciclo em torno de 120 dias e ela desenvolve-se bem no período de fevereiro a novembro.

$O$ delineamento utilizado foi o de blocos inteiramente casualizados (DBC), com seis tratamentos e quatro repetições. Os tratamentos foram constituídos por seis tensões de água no solo $(20,45,70,95,120$ e $145 \mathrm{kPa})$.

A curva de retenção de água do solo, que representou a camada de $0,1-0,3$ m, foi determinada no Laboratório de Física de Solo da Universidade Federal de Lavras, obtendo a umidade do solo nos pontos de baixas tensões $(2,4,6 \mathrm{kPa})$ e de altas tensões (10, 33, 100, 500 e $1500 \mathrm{kPa})$.

Após o procedimento acima, com ajuda do modelo de VAN GENUCHTEN (1980), descrito pela Equação 1, gerou-se uma equação matemática que traduz o comportamento da umidade do solo em função do potencial matricial:

$\theta=\theta r+\frac{\theta s-\theta r}{\left[1+(\alpha \Psi m)^{\mathrm{n}}\right]^{\mathrm{m}}}$

Em que: $\theta=$ umidade atual com base no volume $\left(\mathrm{cm}^{3} \mathrm{~cm}^{-3}\right) ; \theta_{\mathrm{r}}=$ umidade residual com base no volume $\left(\mathrm{cm}^{3} \mathrm{~cm}^{-3}\right) ; \theta_{\mathrm{s}}=$ umidade de saturação com base no volume; $\varphi_{m}=$ potencial matricial $(\mathrm{kPa}) ; \mathrm{n}$ e $\mathrm{m}=$ Parâmetros de ajuste do modelo; $\alpha=$ representa o inverso da sucção mínima necessária para o início da remoção de água dos macroporos.

Segundo ALVARENGA (2013), $70 \%$ do sistema radicular da cultura do tomateiro se localizam a menos de $0,2 \mathrm{~m}$ da superfície. Sendo assim, foram instalados quatro sensores de matriz granular (GMS), sendo três watermark a 0,2 m de profundidade do solo, que serviram como indicadores indiretos sobre quando e quanto irrigar (tensiômetros de decisão), e um a 0,4 m de profundidade para efeitos de eventuais perdas de água por percolação profunda ou lixiviação de nutrientes, sendo usado o espaçamento ente sensores de 0,6 m.

Foram utilizados 48 sensores de matriz granular (GMS), watermark, sendo instalados três sensores em cada tratamento e instalados em apenas duas repetições para cada tratamento.

Cada parcela experimental teve dimensões de $1,40 \mathrm{~m}$ de largura e 2,90 $\mathrm{m}$ de comprimento $\left(4,06 \mathrm{~m}^{2}\right)$. As parcelas foram compostas por duas fileiras de plantas espaçadas de 1,0 m entre si e 0,60 m entre plantas. Foram consideradas parcelas úteis as compostas pelas plantas centrais (quatro plantas), descartando as bordaduras (Figura 1). 


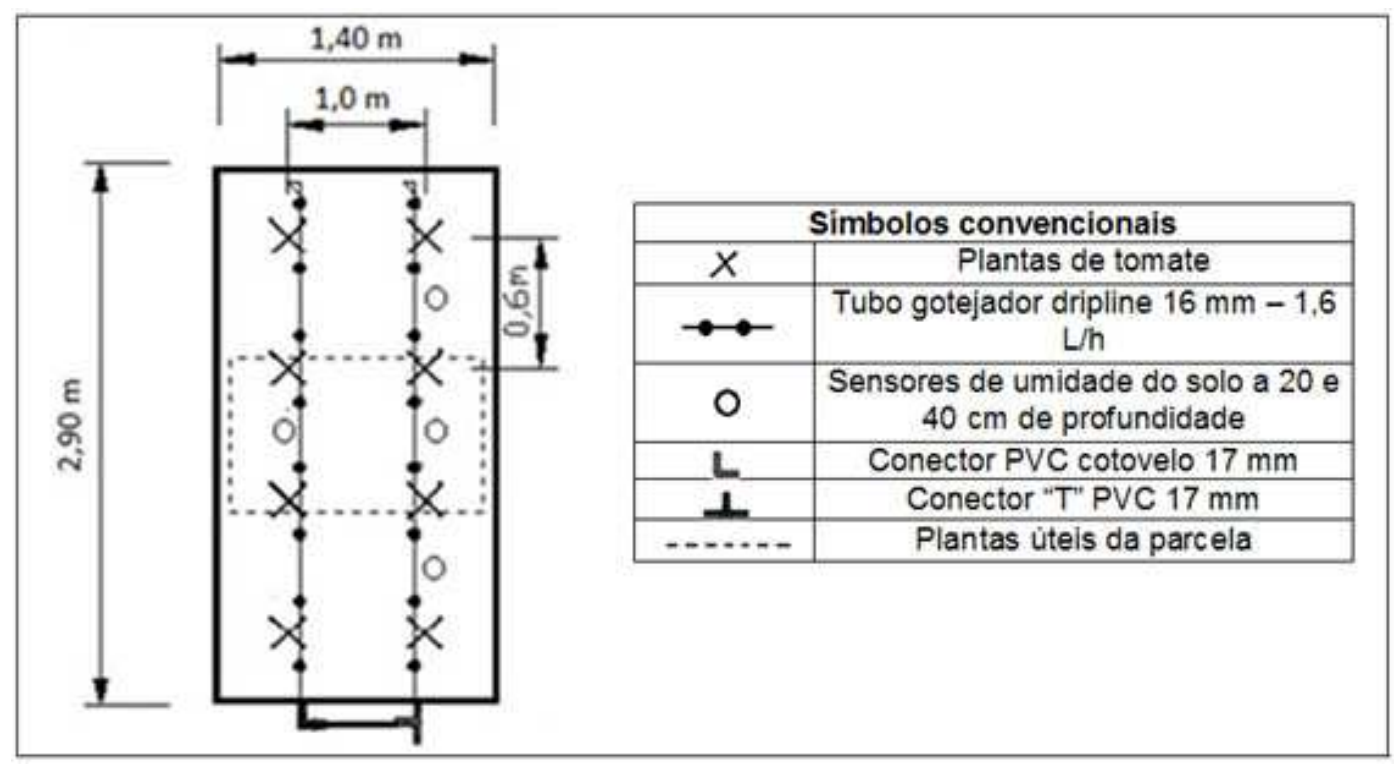

FIGURA 1 - Esquema da parcela experimental com o sistema de irrigação implantado e os sensores de umidade. UFLA, Lavras, MG, 2015.

Fonte: os autores.

O método de irrigação utilizado foi o localizado, com o sistema de irrigação por gotejamento. Uma vez que cada parcela foi composta por duas fileiras de plantas, espaçadas em 1,0 m, em cada linha foi instalado um tubo gotejador a fim de fornecer água às plantas.

A quantidade de água que foi aplicada em cada tratamento foi a necessária para elevar a umidade do solo com base no volume à umidade na capacidade de campo $(10 \mathrm{kPa})$, considerando a profundidade efetiva do sistema radicular de $0,2 \mathrm{~m}$ até a fase de florescimento e de 0,4 $\mathrm{m}$ depois do florescimento.

O tempo de funcionamento do sistema de irrigação em cada tratamento, para elevar a umidade à capacidade de campo, foi calculado com base na Equação 4 e a lâmina bruta foi calculada com base na umidade necessária para elevar a umidade do solo à capacidade de campo no momento de irrigação usando a Equação 3, com dados da lâmina líquida obtida na Equação 2.

$$
\begin{aligned}
& L L=\left(\theta_{c c}-\theta_{\text {atual }}\right) Z \\
& L B=\frac{L L}{E a C U D} \\
& T=\frac{L B A}{e q a}
\end{aligned}
$$

Em que: $L L=$ Lâmina líquida de irrigação $(\mathrm{mm}) ; \theta_{c c}=$ Umidade na capacidade de campo $\left(\mathrm{cm}^{3} \mathrm{~cm}^{-3}\right) ; Z$ = Profundidade efetiva do sistema radicular $(20 \mathrm{~cm}) ; \theta_{\text {atual }}=$ Umidade atual $\left(\mathrm{cm}^{3} \mathrm{~cm}^{-3}\right) ; \mathrm{LB}=$ Lâmina bruta $(\mathrm{mm}) ; \mathrm{Ea}=$ Eficiência de aplicação do sistema; CUD = Coeficiente de uniformidade de distribuição do sistema de irrigação; $T$ = Tempo de irrigação para elevar a umidade do solo à capacidade de campo (horas); $A=$ área ocupada por planta $\left(\mathrm{m}^{2}\right) ; \mathrm{qa}=$ vazão média dos emissores $\left(\mathrm{L} \mathrm{h}^{-1}\right)$; e = número de emissores por planta (dois emissores). 
Do transplantio até o início da diferenciação dos tratamentos (18 dias), foram feitas irrigações diárias repondo-se a lâmina correspondente à tensão de $13 \mathrm{kPa}$, equivalente a uma lâmina bruta de $6,43 \mathrm{~mm}$ de água por parcela, totalizando uma lâmina de $38,58 \mathrm{~mm}$ do transplantio até o início da diferenciação dos tratamentos.

As variáveis analisadas, aos 64 dias após início dos tratamentos, foram: altura da planta, número de folhas, número de cachos, diâmetro do caule e número de frutos. A análise estatística dos dados incluiu-se a análise de variância, com realização do teste $F$, e análises de regressão.

\section{RESULTADOS E DISCUSSÃO}

Na Figura 2 é apresentada a regressão para a altura do tomateiro, Dominador $\mathrm{F} 1$, em diferentes tensões de água no solo.

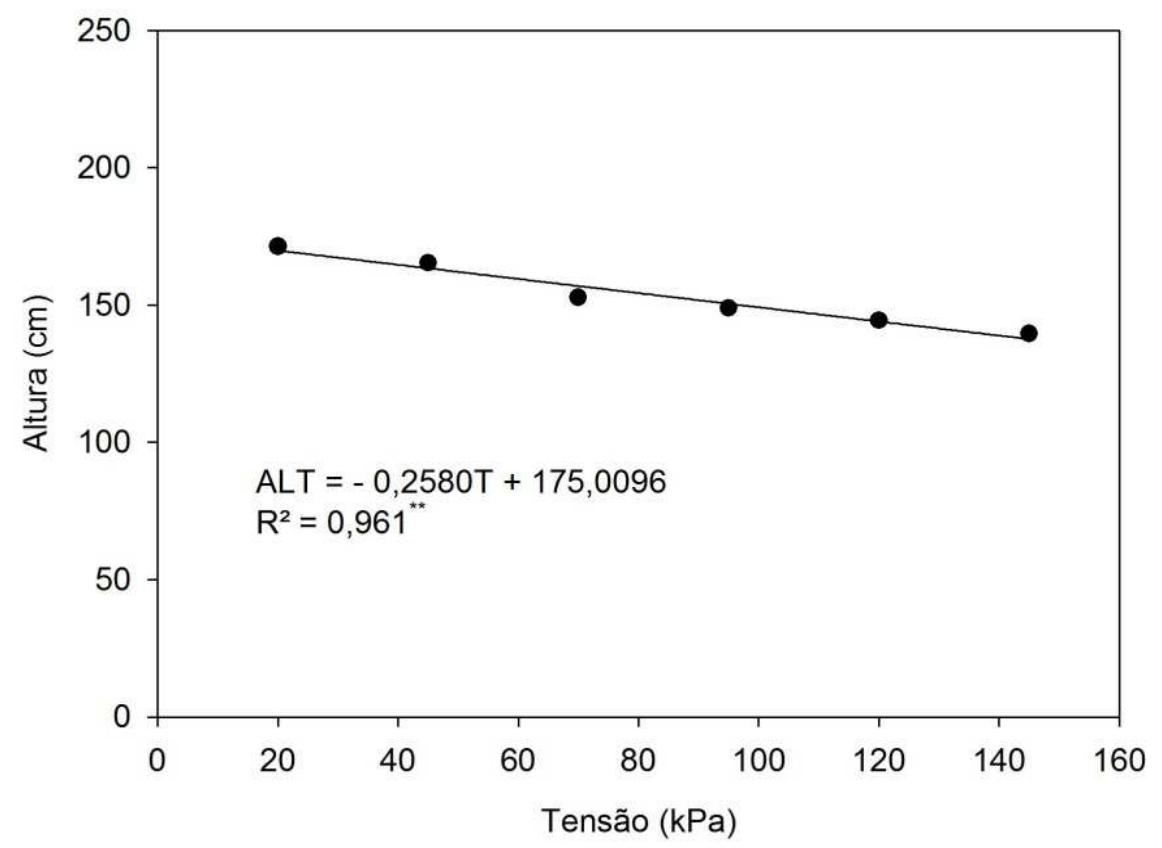

FIGURA 2 - Altura do tomateiro Dominador F1 em função de diferentes tensões de água no solo.

** Significativo a $1 \%$ de probabilidade pelo teste $\mathrm{F}$.

Observa-se na Figura 2 que a altura do tomateiro foi influenciada pelo aumento da tensão de água no solo. A maior altura foi obtida na tensão de $20 \mathrm{kPa}(170,69$ $\mathrm{cm})$, reduzindo linearmente até a tensão de $145 \mathrm{kPa}$.

$\mathrm{O}$ aumento da tensão de água no solo em uma unidade $(\mathrm{kPa})$, de acordo com a equação gerada, implicará em uma redução da altura por planta em 0,26, considerando o intervalo estudado e que $96,10 \%$ das variações dessa variável, em função das tensões de água no solo, podem ser explicadas pela regressão linear.

SOARES et al. (2011) também observaram redução da altura de planta de tomateiro (cultivar Nemadouro) com a redução da lâmina d'água aplicada, obtendo altura máxima de $85,10 \mathrm{~cm}$ com a maior disponibilidade hídrica fornecida, corroborando com os dados deste trabalho.

As variações ocorridas no número de folhas por planta podem ser explicadas pela regressão linear inversa, a 1\% de probabilidade (Figura 3). 


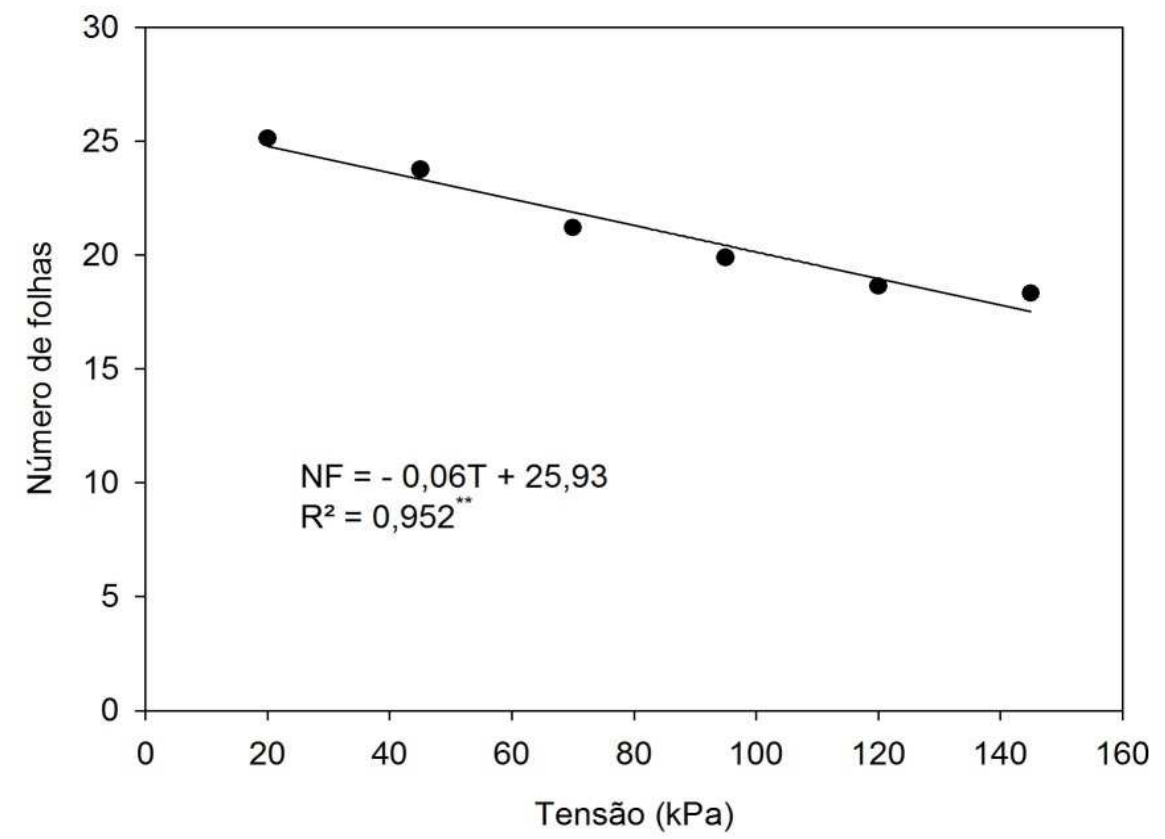

FIGURA 3 - Número de folhas do tomateiro Dominador F1 em função de diferentes tensões de água no solo.

** Significativo a $1 \%$ de probabilidade pelo teste $\mathrm{F}$.

O maior número de folhas foi obtido na tensão de $20 \mathrm{kPa}$, obtendo-se média de 25,13 . Nota-se que, pela equação gerada, com o aumento de uma unidade de tensão há uma redução de 0,06 folhas. De acordo com o coeficiente de determinação gerado, $95,20 \%$ da variação do número de folhas em função das tensões de água no solo, podem ser explicadas pela equação linear gerada.

Resultado semelhante foi obtido por SOARES et al. (2011) e MORALES et al. (2015) encontrando menores números de folhas com a redução do fornecimento de água para o tomateiro. Desta forma, fica evidente o efeito deletério da redução do conteúdo de água no solo sobre o desenvolvimento do tomateiro. A tensão de água no solo teve influência quadrática a $1 \%$ de probabilidade no número de cachos do tomateiro (Figura 4).

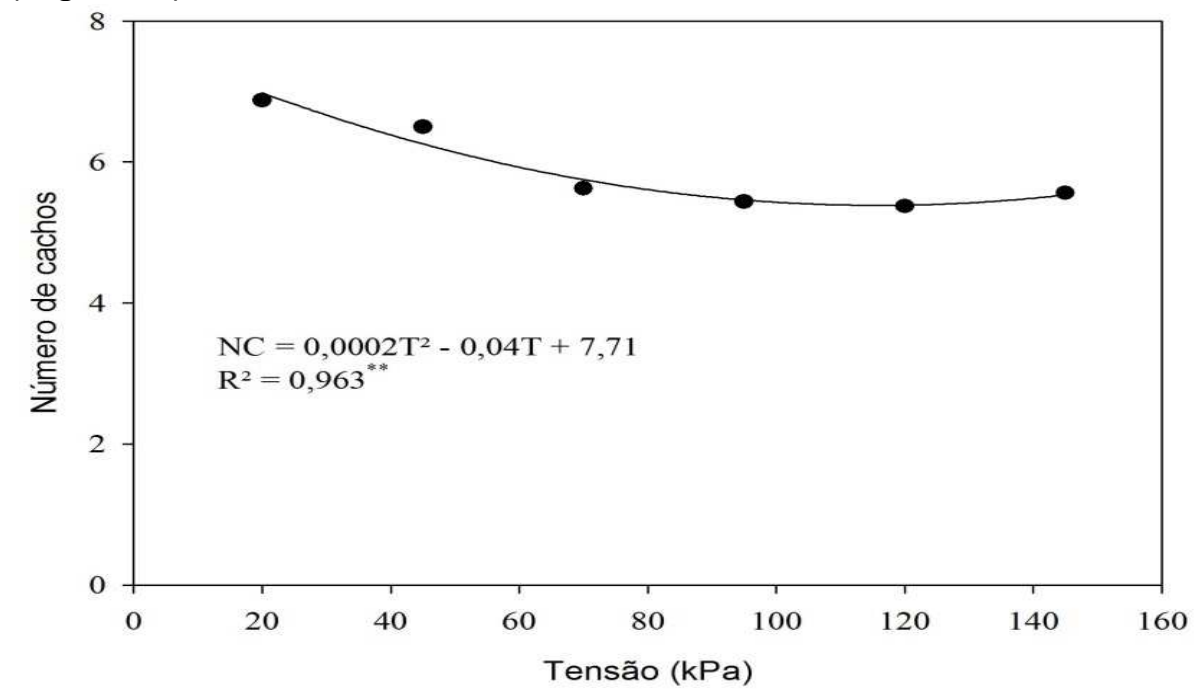

FIGURA 4 - Número de cachos do tomateiro Dominador F1 em função de diferentes tensões de água no solo.

** Significativo a $1 \%$ de probabilidade pelo teste $\mathrm{F}$. 
O maior número de cachos foi obtido na tensão de $20 \mathrm{kPa}$, apresentando 6,88 dessa variável. O ponto de mínima gerada pela equação foi em $100 \mathrm{kPa}$, obtendo média de 5,71 cachos. Nota-se ainda que $96,30 \%$ da variação do número de cachos em função das tensões de água no solo podem ser explicadas pela regressão obtida.

O número de cachos é uma variável de interesse agronômico, uma vez que influenciará diretamente na produção da planta, caso observado por MORALES et al. (2015), onde observaram que a maior produção de frutos por planta foi obtido em $100 \%$ da água disponível no solo, reduzindo linearmente até $25 \%$ da água disponível. $\mathrm{O}$ diâmetro do caule apresentou comportamento quadrático em função das tensões de água no solo a $1 \%$ de probabilidade (Figura 5).

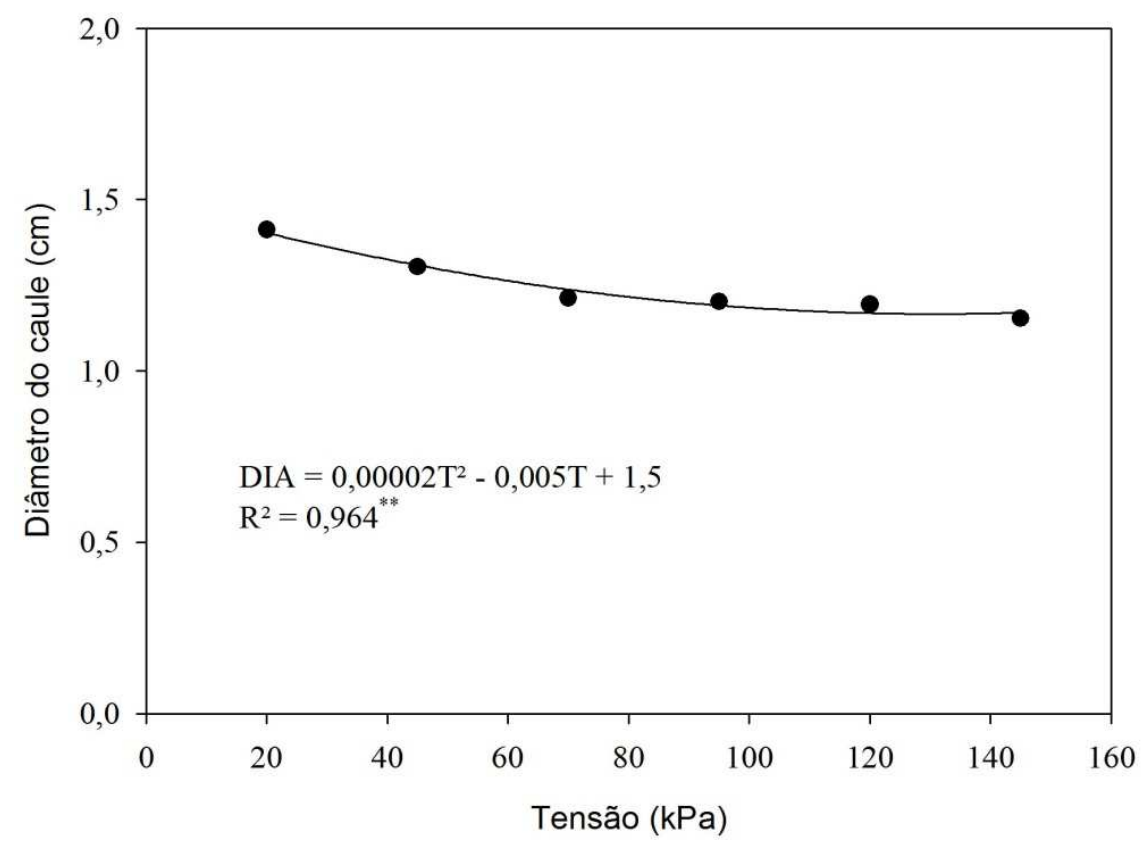

FIGURA 5 - Diâmetro do caule do tomateiro Dominador F1 em função de diferentes tensões de água no solo.

** Significativo a $1 \%$ de probabilidade pelo teste $\mathrm{F}$.

O diâmetro do caule teve uma pequena variação em função das tensões de água no solo. No entanto, o maior valor foi obtido em $20 \mathrm{kPa}(1,41 \mathrm{~cm})$. O ponto de mínima da equação quadrática foi em $125 \mathrm{kPa}$, apresentando diâmetro de $1,19 \mathrm{~cm}$ nesse ponto.

O coeficiente de determinação obtido $\left(R^{2}\right)$ indica que $96,40 \%$ da variação do diâmetro do caule em função das tensões de água no solo pode ser explicada pela regressão quadrática. SOARES et al. (2013) observaram resultados semelhantes, onde a maior lâmina de irrigação (120\% da evapotranspiração real) proporcionou maior diâmetro de caule para o tomateiro cultivar Super Marmande.

De acordo com TAIZ \& ZEIGER (2013) a restrição de água reduz a pressão de turgor e fluxo de seiva pelos vasos condutores, fato que tende a diminuir 0 elongamento celular e, assim, o crescimento e o desenvolvimento das plantas, caso confirmado neste trabalho. Na Figura 6 está apresentada a análise de regressão para o número de frutos obtidos em função das tensões de água no solo. 


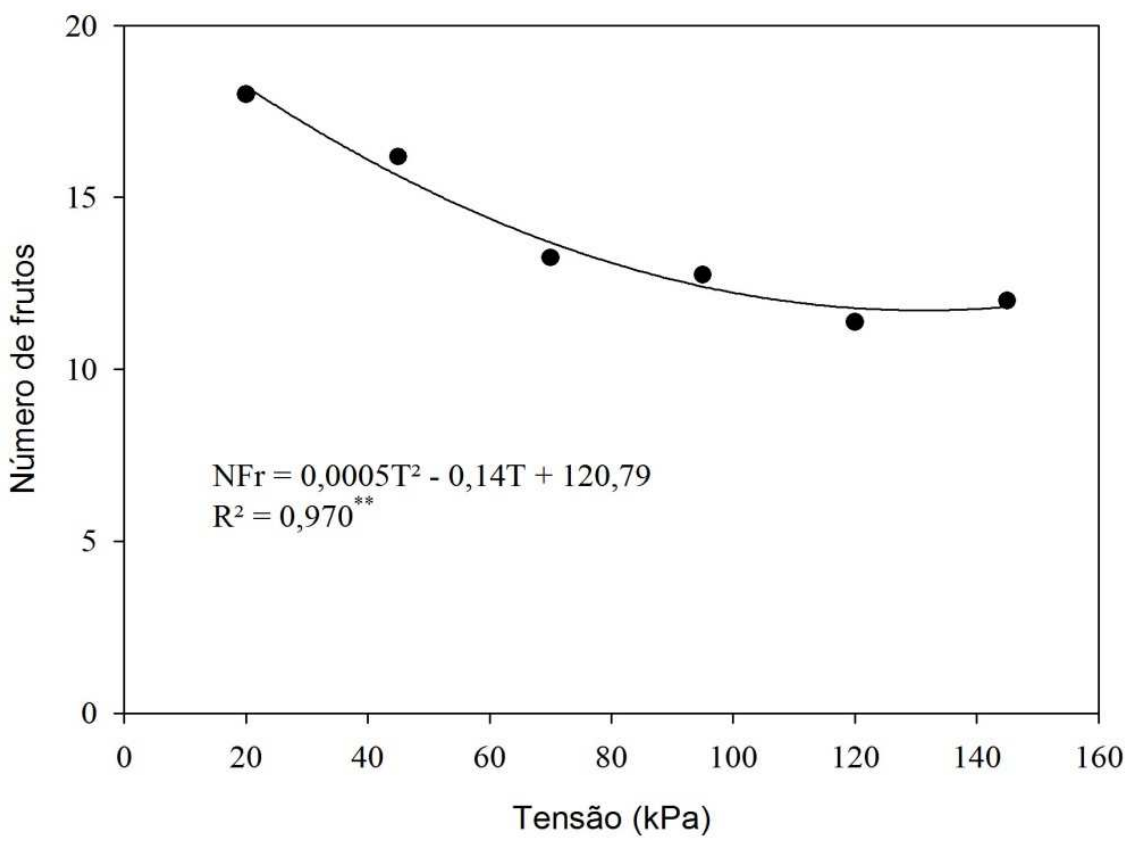

FIGURA 6 - Número de frutos do tomateiro Dominador F1 em função de diferentes tensões de água no solo.

** Significativo a $1 \%$ de probabilidade pelo teste $\mathrm{F}$.

O maior número médio de frutos foi obtido na tensão de $20 \mathrm{kPa}$ (18,19 frutos). Essa variável apresentou comportamento quadrático em função das tensões de água no solo, apresentando ponto de mínima em $140 \mathrm{kPa}$, cujo número de frutos foi de 11,00 . Nota-se ainda que $97 \%$ da variação do número de frutos em função das tensões de água no solo pode ser explicado pela regressão quadrática obtida.

SILVA et al. (2013), ao avaliarem diferentes níveis de reposição de água para o tomateiro cultivar Caline IPA 6 , observaram produção máxima de frutos $(37,40$ frutos) na reposição de $110 \%$ da evapotranspiração da cultura (ETc). MORALES et al. (2015), ao avaliarem dois tipos de materiais de tomateiro (cultivar M-82 e linhagem TOM-684), também observaram redução linear da produção de frutos do tomateiro em menores conteúdos de água no solo até $25 \%$ da água disponível no solo.

Torna-se necessário avaliar a influência de diferentes tensões de água no solo sobre o tomateiro, uma vez que para cada cultivar e/ou variedade, tem-se necessidade hídrica diferente, como constatado por HOTT et al. (2014), ao avaliarem a cultivar de tomate Alambra, observaram que tensões menores que 25 $\mathrm{kPa}$ não são necessários durante a fase vegetativa dessa cultivar.

Para as condições do presente trabalho, observou-se que para as variáveis altura e número de folhas houve decréscimo linear com a redução da tensão de água no solo até $140 \mathrm{kPa}$. E para as variáveis número de cachos, de frutos e diâmetro do caule, houve redução quadrática até a tensão de $140 \mathrm{kPa}$. Esses resultados demonstram um menor desenvolvimento do tomateiro com menores conteúdos de água no solo (maiores tensões). 
A altura, o número de folhas, número de cachos, diâmetro do caule e número de frutos do tomateiro, híbrido Dominador $\mathrm{F} 1$, foi influenciado pelo aumento da tensão de água no solo.

Os maiores valores dessas variáveis foram obtidos na tensão de $20 \mathrm{kPa}$, com o sensor instalado a 0,20 $\mathrm{m}$ de profundidade.

\section{REFERÊNCIAS}

ALVARENGA, M. A. R. Tomate: produção em campo, casa de vegetação e hidroponia. 2 ed. rev. e amp., Lavras: Editora Universitária de Lavras, 2013, 455p.

FAO (2013). Food and Agriculture Organization of the United Nations. Disponível em: <http://www.faostat.fao.org>. Acesso em 10 de Setembro de 2014.

GUALBERTO, R.; OlIVEIRA, P. S. R.; GUIMARÃES, A. M. Desempenho de cultivares de tomateiro para mesa em ambiente protegido. Horticultura Brasileira, Brasília, v. 25, n. 4, p. 244-246, out. 2007. DOI - 10.1590/S010205362007000200022

HOTT, M. de O.; LIMA, V. L. de S.; PEREIRA, L. R.; SOUZA, J. M. de; REIS, E. F. dos. Produção de biomassa na fase vegetativa do tomateiro em função da tensão de água no solo. Enciclopédia Biosfera, Goiânia, v.10, n.18; p. 2389-2398, 2014. Disponível

em: http://www.conhecer.org.br/enciclop/2014a/AGRARIAS/producao\%20de\%20biomass a.pdf

IBGE (2013). Instituto Brasileiro de Geografia e Estatística. Disponível em <

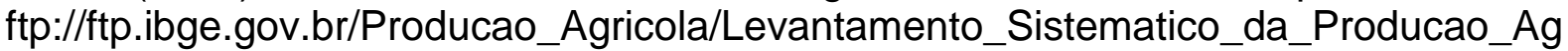
ricola_[mensal]/Fasciculo/2013/lspa_201308.pdf>. Acesso em 10 de novembro 2015.

KUŞÇU, H; TURHANA, A.; DEMIR, A. O. The response of processing tomato to deficit irrigation at various phenological stages in a sub-humid environment. Agricultural Water Management, Amsterdam, v. 133, p. 92- 103, 2014. DOI 10.1016/j.agwat.2013.11.008

MORALES, R. G. F.; RESENDE, L. V.; BORDINI, I. C.; GALVÃO, A. G.; REZENDE, F. C. Caracterização do tomateiro submetido ao déficit hídrico. Scientia Agraria, Curitiba, v. 16, n. 1, p. 09-17, 2015. Doi: http://dx.doi.org/10.5380/rsa.v16i1.41042

MUKHERJEE, A.; SARKAR, S.; CHAKRABORTY, P. K. Marginal analysis of water productivity function of tomato crop grown under different irrigation regimes and mulch managements. Agricultural Water Management, Bursa, v. 104, p. 121-127, 2012. DOI - 10.1016/j.agwat.2011.12.006

OZBAHCE, A.; TARI, A. F. Effects of different emitter space and water stress on yield and quality of processing tomato under semi-arid climate conditions. Agricultural Water Management, Amsterdam, v. 97, n. 1, p. 1405-1410, 2010. DOI 10.1016/j.agwat.2010.04.008 
SÁ, N. S. A. de.; PeReiRA, G. M.; ALVARENGA, M. A. R.; MATTIOLI, W.; CARVALHO, J. de A. Comportamento da cultura do tomateiro sob diferentes tensões de água no solo em ambiente protegido. Revista brasileira de engenharia agrícola e ambiental, Campina Grande, v.9, n.3, p.341-347, 2005. DOI http://dx.doi.org/10.1590/S1415-43662005000300008

SAMAILA, A.; AMANS, E. B.; ABUBAKAR, I. U.; BABAJI, B. A. Nutritional quality of tomato (Lycopersicon esculentum mill) as influenced by mulching, nitrogen and irrigation interval. Journal of Agricultural Science, Toronto, v. 3, n. 1, p. 266-270, 2011. DOI - http://dx.doi.org/10.5539/jas.v3n1p266

SGN - Solanaceae Genome Network. Disponível em: <http://sgn.cornell.edu/>. Acesso em 10 de novembro de 2015.

SILVA, J. M.; FERREIRA, R. S.; MELO, A. S.; SUASSUNA, J. F.; DUTRA, A. F.; GOMES, J. P. Cultivo do tomateiro em ambiente protegido sob diferentes taxas de reposição da evapotranspiração. Revista Brasileira de Engenharia Agrícola e Ambiental, Campina Grande, v. 17, n. 1, p. 40-46, 2013. DOI http://dx.doi.org/10.1590/S1415-43662013000100006

SOARES, L. A. A.; LIMA, G. S.; BRITO, M. E. B.; SÁ, F. V. S.; ARAÚJO, T. T. Crescimento do tomateiro e qualidade física dos frutos sob estresse hídrico em ambiente protegido. Revista Verde, Mossoró, v. 6, n. 3, p. 203-212, 2011. Disponível

em:

http://www.gvaa.com.br/revista/index.php/RVADS/article/view/827/742

SOARES, L. A. dos A.; BRITO, M. E. B.; ARAÚJO, T. T. de; SÁ, F. V. da; SILVA, E. C. B. da. Morfofisiologia e qualidade pós-colheita do tomateiro sob estresse hídrico nas fases fenológicas. Revista Verde de Agroecologia e Desenvolvimento Sustentável, Mossoró, v. 8, n. 1, p. 239-246, $2013 . \quad$ Doi: http://dx.doi.org/10.18378/rvads.v8i1.2001

SUN, Y.; FENG, H; LIU, F. Comparative effect of partial root-zone drying and deficit irrigation on incidence of blossom-end rot in tomato under varied calcium rates. Journal of Experimental Botany, Oxford, v. 64, n. 7, p. 2107-2116, 2013. DOI 10.1093/jxb/ert067

TAIZ, L.; ZEIGER, E. Fisiologia vegetal. 5. ed. Porto Alegre: Artmed, 2013. 918p.

WANG, Y.; LIU, F.; JENSEN, C. R. Comparative effects of deficit irrigation and alternate partial root-zone irrigation on xylem ph, aba and ionic concentrations in tomatoes. Journal of Experimental Botany, Oxford, v. 63, n. 5, p. 1-11, 2012. DOI $10.1093 / \mathrm{jxb} / \mathrm{err} 370$ 